\title{
To Give or Not to Give: RhD Immunoglobulin for an RHD*39 Pregnant Woman with Sickle Cell Disease
}

\author{
Justin E. Juskewitch Craig D. Tauscher Sheila K. Moldenhauer Jennifer E. Schieber \\ Eapen K. Jacob Margaret A. DiGuardo \\ Division of Transfusion Medicine, Mayo Clinic, Rochester, MN, USA
}

\author{
Keywords \\ Sickle cell disease $\cdot$ Pregnancy $\cdot \mathrm{RhD}$ immunoglobulin · \\ RHD*39
}

\begin{abstract}
Introduction: Patients with sickle cell disease (SCD) have repeated episodes of red blood cell (RBC) sickling and microvascular occlusion that manifest as pain crises, acute chest syndrome, and chronic hemolysis. These clinical sequelae usually increase during pregnancy. Given the racial distribution of SCD, patients with SCD are also more likely to have rarer $\mathrm{RBC}$ antigen genotypes than $\mathrm{RBC}$ donor populations. We present the management and clinical outcome of a 21-year-old pregnant woman with SCD and an RHD*39 (RhD[S103P], G-negative) variant. Case Presentation: Ms. S is $B$ positive with a reported history of anti-D, anti-C, and anti-E alloantibodies (anti-G testing unknown). Genetic testing revealed both an $R H D^{*} 39$ and homozygous partial RHCE*ceVS.02 genotype. Absorption/elution testing confirmed the presence of anti-G, anti-C, and anti-E alloantibodies but could not definitively determine the presence/absence of an anti-D alloantibody. Ms. S desired to undergo elective pregnancy termination and the need for postprocedural RhD immunoglobulin (RhIG) was posed. Given that only the $\mathrm{G}$ antigen site is changed in an $R H D^{*} 39$ genotype and the potential risk of RhIG triggering a hyperhemolytic episode in an SCD patient, RhIG was not administered. There were no procedural complications. Follow-up testing at 10 weeks showed no increase in RBC alloantibody strength. Discussion/Conclusion: Ms. S represents a rare RHD*39 and partial $R H C E^{*}$ ceVS.02 genotype which did not further alloim-
\end{abstract}

munize in the absence of RhIG administration. Her case also highlights the importance of routine anti-G alloantibody testing in women of childbearing age with apparent anti-D and anti-C alloantibodies.

(c) 2021 S. Karger AG, Basel

\section{Introduction}

Sickle cell disease (SCD) is an inherited hemoglobinopathy characterized by hemoglobin $\mathrm{S}$ polymerization leading to red blood cell (RBC) sickling, poor oxygen delivery, persistent RBC membrane deformities, and recurrent episodes of microvasculature occlusion $[1,2]$. Common clinical sequelae for patients with SCD include autosplenectomy by adulthood, chronic RBC hemolysis, pain crises, acute chest syndrome, cerebrovascular events, priapism, and secondary pulmonary hypertension $[1,2]$. Long-term management strategies to prevent such sequelae often include hydroxyurea, L-glutamine, chronic $\mathrm{RBC}$ transfusion/exchange, and vaccinations against encapsulated bacteria [1-3]. Pregnancy can further exacerbate the occurrence of pain crises, thromboses, and infection with additional risk to the fetus of intrauterine growth restriction and low birth weight [2, 4-7]. As such, transfusion support often plays a key role in disease management during pregnancy.

SCD patients receiving transfusion support, however, generate RBC alloantibodies at higher rates that other patient populations, in part due to the proinflammatory nature of their hemoglobinopathy and in part due to differences in expression patterns of common RBC antigens 
Table 1. Serologic RBC phenotype for Ms. S completed at 8 years of age; all positive and negative control cells tested for quality control met the acceptance criteria on the day of testing

\begin{tabular}{ll}
\hline Blood group antigen & Serologic phenotype result \\
\hline $\mathrm{ABO}$ & $\mathrm{B}$ \\
$\mathrm{D}$ & $3+$ \\
$\mathrm{C}$ & negative \\
$\mathrm{C}$ & $4+$ \\
$\mathrm{E}$ & negative \\
$\mathrm{e}$ & $4+$ \\
$\mathrm{K}$ & negative \\
$\mathrm{Jk}^{\mathrm{a}}$ & $2+$ \\
$\mathrm{Jk}^{\mathrm{b}}$ & negative \\
$\mathrm{Fy}^{\mathrm{a}}$ & negative \\
$\mathrm{Fy}^{\mathrm{b}}$ & negative \\
$\mathrm{M}$ & negative \\
$\mathrm{N}$ & $2+$ \\
$\mathrm{S}$ & negative \\
$\mathrm{S}$ & $2+$ \\
$\mathrm{Le}^{\mathrm{a}}$ & negative \\
$\mathrm{Le}^{\mathrm{b}}$ & $2+$ \\
$\mathrm{P}_{1}$ & $4+$ \\
\hline
\end{tabular}

$\mathrm{RBC}$, red blood cell.

between SCD patient and predominantly Caucasian RBC donor populations (e.g., C, E, K, Fy ${ }^{\mathrm{a}}$ ) [8-12]. SCD patient populations are also enriched for rarer $\mathrm{RBC}$ antigen genotypes that are more common in African-American populations. As such, these rarer RBC antigens can create additional management challenges during pregnancy and the peripartum period. Herein, we describe the management strategy, outcome, and broader transfusion medicine challenges highlighted by a pregnant AfricanAmerican woman with SCD and a rare $R H D^{*} 39$ variant (also known as an $\mathrm{RhD}[\mathrm{S} 103 \mathrm{P}]$, G-negative variant) caused by a c.307T $>C$ change.

\section{Case Presentation}

Ms. S first presented at 8 years of age with a history of SCD and 4 days of fevers. She was anemic at presentation (hemoglobin 6.6 $\mathrm{g} / \mathrm{dL}$ ) and diagnosed with acute chest syndrome and pneumonia on chest X-ray. At that time, her RBC antibody screen by tube methodology was negative. Three other medical institutions in which she had received care were contacted for RBC antibody testing results, but no results could be obtained. An extended serologic RBC antigen phenotype was completed to facilitate preparation of D, C, E, and $\mathrm{K}$ antigen-matched RBC units for transfusion (Table 1). She was treated with simple blood transfusion, supplemental oxygen, and antimicrobials and then dismissed from the hospital.

Ms. S returned at 21 years of age through the emergency department with new-onset upper and lower left extremity pain of 1 day's duration. She was not pregnant at this time. She had received medical care at other institutions during the interim, including multi-
Table 2. Imputed RBC phenotype by PreciseType HEA Molecular BeadChip $^{\mathrm{TM}}$ testing for Ms. S completed at 18 years of age; testing also detected homozygosity for partial $R H C E^{*} c e V S .02$ alleles (Cys16 and Val245)

\begin{tabular}{|c|c|c|}
\hline Blood group & Antigen & Genotype result \\
\hline \multirow[t]{6}{*}{$\mathrm{Rh}$} & C & 0 \\
\hline & $c$ & + \\
\hline & $\mathrm{E}$ & 0 \\
\hline & $\mathrm{e}$ & + \\
\hline & $\mathrm{V}$ & + \\
\hline & VS & + \\
\hline \multirow[t]{6}{*}{ Kell } & $\mathrm{K}$ & 0 \\
\hline & $\mathrm{k}$ & + \\
\hline & $\mathrm{Kp}^{\mathrm{a}}$ & 0 \\
\hline & $\mathrm{Kp}^{\mathrm{b}}$ & + \\
\hline & $\mathrm{Js}^{\mathrm{a}}$ & 0 \\
\hline & $\mathrm{Js}^{\mathrm{b}}$ & + \\
\hline \multirow[t]{2}{*}{ Kidd } & $\mathrm{Jk}^{\mathrm{a}}$ & + \\
\hline & $\mathrm{Jk}^{\mathrm{b}}$ & 0 \\
\hline \multirow[t]{2}{*}{ Duffy } & $\mathrm{Fy}^{\mathrm{a}}$ & 0 \\
\hline & $\mathrm{Fy}^{\mathrm{b}}$ & $0^{*}$ \\
\hline \multirow[t]{5}{*}{ MNS } & $\mathrm{M}$ & 0 \\
\hline & $\mathrm{N}$ & + \\
\hline & $S$ & 0 \\
\hline & s & + \\
\hline & $\mathrm{U}$ & + \\
\hline \multirow[t]{2}{*}{ Lutheran } & $\mathrm{Lu}^{\mathrm{a}}$ & 0 \\
\hline & $\mathrm{Lu}^{\mathrm{b}}$ & + \\
\hline \multirow[t]{2}{*}{ Diego } & $\mathrm{Di}^{\mathrm{a}}$ & 0 \\
\hline & $\mathrm{Di}^{\mathrm{b}}$ & + \\
\hline \multirow[t]{2}{*}{ Colton } & $\mathrm{Co}^{\mathrm{a}}$ & + \\
\hline & $\mathrm{Co}^{\mathrm{b}}$ & 0 \\
\hline \multirow[t]{4}{*}{ Dombrock } & $\mathrm{Do}^{\mathrm{a}}$ & + \\
\hline & $\mathrm{Do}^{\mathrm{b}}$ & + \\
\hline & Hy & + \\
\hline & $\mathrm{Jo}^{\mathrm{a}}$ & + \\
\hline \multirow[t]{2}{*}{ Landsteiner-Wiener } & $\mathrm{LW}^{\mathrm{a}}$ & + \\
\hline & $\mathrm{LW}^{\mathrm{b}}$ & 0 \\
\hline \multirow[t]{2}{*}{ Scianna } & Sc1 & + \\
\hline & Sc2 & 0 \\
\hline Hemoglobin S & $\mathrm{HbS}$ & ++ \\
\hline
\end{tabular}

RBC, red blood cell. * GATA silencing mutation present.

ple blood transfusions. She had a history of deep vein thrombosis and pulmonary embolism at 18 years of age along with a diagnosis of moyamoya disease following a cerebrovascular accident at 20 years of age. Her baseline hemoglobin was known to be at 8.5-9.5 $\mathrm{g} / \mathrm{dL}$. Blood bank history received from an outside medical institution indicated presence of anti-D, anti-C, and anti-E alloantibodies. She had also received two RBC transfusions 2 months prior that were negative for the $\mathrm{D}, \mathrm{C}, \mathrm{E}, \mathrm{K}, \mathrm{Fy}^{\mathrm{a}}$, Jk $\mathrm{J}^{\mathrm{b}}$, and $\mathrm{S}$ antigens. RBC molecular genotyping had also been performed by the outside institution; it was in agreement with her previous serologic pheno- 

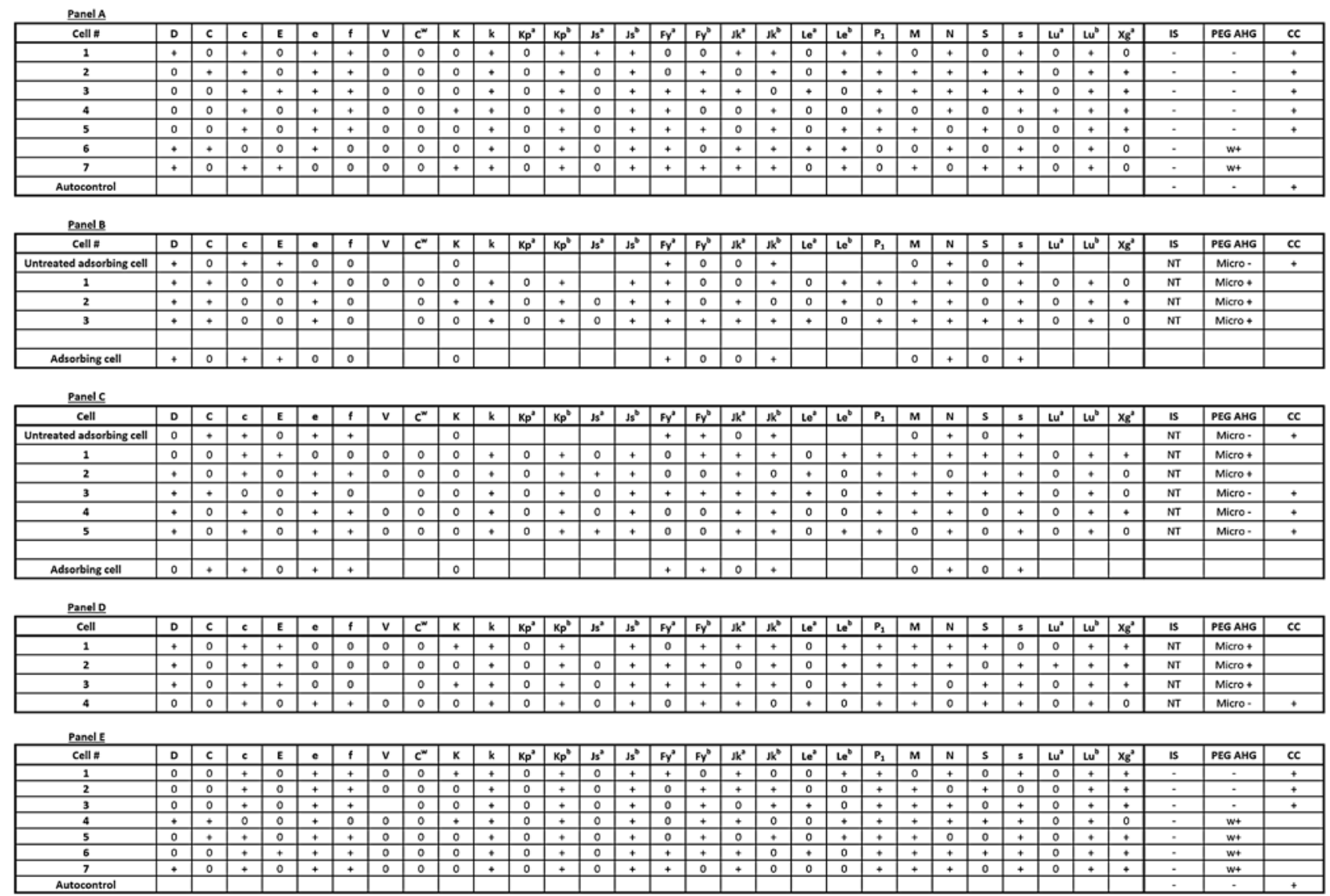

Fig. 1. Initial plasma $R B C$ antibody identification (panel A), R2R2 adsorption and adsorbate RBC antibody identification (panel B), r'r adsorption and adsorbate RBC antibody identification (panel C), elution from adsorbing r'r cells and eluate RBC antibody identification (panel D), and subsequent plasma RBC antibody identi-

type, but also revealed the presence of a Duffy erythrocyte promoter GATA mutation (Table 2) and homozygosity for the partial RHCE* ${ }^{*}$ VVS.02 allele. Antibody identification using tube methodology at that time also identified what appeared to be the presence of anti-D, anti-C, and anti-E alloantibodies (panel not shown). An anti-G antibody was not interrogated for at this point since she was not pregnant; it was not known whether an anti-G was interrogated for by the outside institution that also detected these apparent anti-D and anti-C alloantibodies. Given her positive $\mathrm{RhD}$ status, she was presumed to be a partial D phenotype and provided $\mathrm{D}, \mathrm{C}, \mathrm{E}$, and $\mathrm{K}$ antigen-negative RBC unit transfusions as part of her clinical care. She was then dismissed from the hospital with several subsequent follow-up outpatient visits.

Several months later, Ms. S returned through the emergency department with a 4-day history of bilateral thigh pain as well as vaginal bleeding. She was now 7 weeks pregnant by last menstrual period and confirmed by transvaginal ultrasound. Initial serum $\mathrm{RBC}$ antibody identification using tube technology was only positive for panel cells expressing both the $\mathrm{D}$ and $\mathrm{C}$ or $\mathrm{D}$ and $\mathrm{E}$ antigens (Fig. 1, panel A). Given her pregnancy status, testing for an anti-G alloantibody was pursued at this point. Serum adsorption using R2R2 cells confirmed the presence of an anti-C alloantibody (Fig. 1, panel B). While separate serum adsorption using r'r cells fication (panel E). All testing panels were performed using tube methodology, and the last wash from eluate preparation (panel D) was negative for the presence of RBC antibodies (data not shown). CC, check cells; IS, immediate spin; NT, not tested; PEG AHG, polyethylene glycol antihuman globulin; RBC, red blood cell. confirmed the presence of an anti-E alloantibody, only one of the four D+ cells tested against this adsorbate showed reactivity, making it unclear whether an anti-D alloantibody was present versus an alloantibody to a low-incidence antigen (Fig. 1, panel C). Elution of the antibodies adsorbed to the r'r cells confirmed the presence of an anti-G alloantibody (Fig. 1, panel D). Serologic RBC phenotyping for the $\mathrm{G}$ antigen (not previously performed) confirmed that she lacked the $G$ antigen.

Ms. S desired to electively terminate her pregnancy, so the question about the need for RhD immunoglobulin (RhIG) after her dilatation and curettage was posed by her clinical team. Additional DNA sequencing of her $R H D$ allele had been completed earlier that year by an outside institution and had revealed only the presence of an $R H D^{*} 39$ variant, an RhD Ser103Pro variant ( $R H D$ c.T307C) which eliminates the $\mathrm{G}$ antigen site on the $\mathrm{RhD}$ protein. The remainder of her RHD exons matched the established consensus sequence for $R H D$.

Several considerations were weighed in the decision of whether or not to give RhIG to Ms. S following her dilatation and curettage. Normally, the risk/benefit profile of RhIG favors its use, given its proven clinical effectiveness and low risk profile. For Ms. S, however, the potential benefit of RhIG was lessened and the potential harm was increased. Given her $R H D$ variant, the only $\mathrm{RhD}$ alloan- 
tibody she theoretically should form upon $\mathrm{RhD}$ antigen exposure would be an anti-G alloantibody. Thus, she had already formed the only "anti-RhD" alloantibody that she could. Since Ms. S lacked only the $\mathrm{G}$ epitope, most (if not all) anti-D antibody specificities in the RhIG would bind to her own RBC. Given that her circulating RBCs greatly outnumber any circulating fetal RBCs released from a firsttrimester fetus, it was unclear whether any RhIG would bind to any potentially RhD-positive fetal RBCs even if present. From a harm perspective, the introduction of passive anti-D antibodies binding to her RBCs could serve as a hyperhemolysis trigger in an SCD patient. While there are no reports of RhIG triggering such an event in an SCD patient, it has been reported that the reverse - transfusion of allogeneic RBCs against which an SCD patient has already generated an alloantibody - can trigger hyperhemolysis [13-16].

The decision was made not to administer RhIG to Ms. S following her dilatation and curettage. The procedure did not have any complications, with an estimated blood loss of $20 \mathrm{~mL}$. She was seen in follow-up 10 weeks later. Her workups revealed unchanged weak reactivity consistent with her known anti-G, anti-C, and anti-E alloantibodies (Fig. 1, panel E). She also had a negative direct antiglobulin test at 10-week follow-up.

\section{Discussion/Conclusion}

The clinical course of Ms. S, a pregnant woman with SCD and both RHD*39 and RHCE*ceVS.02 variants, highlights several important features. First and foremost, she represents an unusual $\mathrm{RhD}$ variant in which only the $\mathrm{G}$ antigen site is changed [17-19]. Moreover, the other reported instances of this $\mathrm{RhD}$ variant were in association with $\mathrm{RhCE} \mathrm{cE} / \mathrm{ce}$ [17]. Ms. S is homozygous for RhCE ce/ ce instead, with additional variant RHCE gene sequence changes (Table 2).

Furthermore, Ms. S's case nicely illustrates the important role that genetic interrogation of RBC antigens can directly play in important clinical care decisions. The information obtained from her genomic $\mathrm{RhD}$ sequencing highlighted both the extent of "anti-RhD" alloantibodies she could theoretically generate and the extent to which RhIG would likely bind to her own RBCs. Given her SCD and increased risk for hyperhemolytic episodes, such genomic information clarified the expected scope of benefit and potential harm for RhIG to personalize her clinical care. Importantly, there was no change in her RBC antibody testing at 10-week follow-up despite not administering RhIG.

Like many patients, Ms. S's clinical care is spread across several healthcare system networks and, as such, her transfusion history and related test results are disjointed or incomplete. Transfusion services often have to rely on patient self-reporting, chart reviews, and linked electronic health records for pertinent clinical information such as a previously detected but now undetectable $\mathrm{RBC}$ alloantibody to help prevent delayed serologic and hemolytic transfusion reactions $[15,20,21]$. Even when specific healthcare systems are identified, comprehensive information about specific nuances of laboratory testing (e.g., distinguishing between anti-D, anti-C, and anti- $\mathrm{G}$ alloantibodies) may not be obtainable.

Ms. S's case highlights the need for routine anti-G antibody testing for women of childbearing age who have apparent anti-D and anti-C antibodies on RBC antibody testing. While such a distinction is not necessary for transfusion decisions, the presence or absence of anti-D alloantibody becomes critical in decisions regarding RhIG administration. As RBC antibody titers wax and wane over time, definitively establishing the presence of a true anti-D alloantibody versus an anti-G alloantibody when antibody strengths are higher can prevent testing issues that may occur later when antibody titers have waned (Fig. 1, panel C) [22-24]. RBC antibody testing results are also rather unique in nature amongst laboratory testing results as they are additive - once a given $\mathrm{RBC}$ alloantibody is detected/reported, it is considered present even if it is not currently detectable [25]. As such, the reporting of an anti-D alloantibody in the medical record of a woman with apparent anti-D and anti-C alloantibodies without assuring it is truly an anti-D alloantibody can lead to pregnant/postpartum women not receiving appropriate RhIG therapy. Such an approach does entail significant additional work on behalf of the immunohematology laboratory staff until a true anti-D alloantibody is detected, but the missed opportunities to prevent further alloimmunization and hemolytic disease of the fetus and newborn are equally as significant.

Moreover, the decision to administer RhIG to a pregnant/postpartum woman is often made by our nontransfusion clinical colleagues who only look for the combination of $\mathrm{RhD}$-negative status and the lack of an anti-D antibody. The subtle nuances of anti-D versus anti-G and when such distinctions have been made versus not are only normally appreciated by transfusion medicine staff. As such, our clinical colleagues rely on reported results to be accurate, such that a reported anti-D alloantibody is a true anti-D alloantibody. Furthermore, in the era of readily available laboratory testing results amongst clients of the same vended electronic health record or from regional/national RBC antibody registries, our clinical colleagues may also rely on outside RBC antibody testing results to guide such decisions [26, 27]. In an era of increased electronic sharing of testing data, the need for a universal practice of anti-G antibody testing for women of childbearing age who have apparent anti-D and anti-C antibodies has become all the more important.

In summary, this work describes the clinical course of a pregnant woman with $\mathrm{SCD}$ and both rare $\mathrm{RhD}\left(R H D^{*} 39\right)$ and partial RhCE (RHCE* ceVS.02) variants whose RBC antibody testing showed unchanged weak reactivity consistent with her known anti-G, anti-C, and anti-E alloantibodies after an elective first-trimester dilatation and curettage. Her case demonstrates the unique phenotype of 
the $R H D^{*} 39$ variant (loss of $\mathrm{G}$ antigen only) and the results of withholding RhIG. Furthermore, in the setting of presumed anti-D and anti-C antibodies, her case also highlights the need for routine confirmation of the presence of an anti-D alloantibody as opposed to an anti-G alloantibody in women of childbearing age, rather than just at the time of pregnancy.

\section{Acknowledgment}

We would like to thank our immunohematology laboratory staff whose testing is presented in this work.

\section{Statement of Ethics}

Written informed consent was obtained from the patient for publication of this case report and any accompanying images.

\section{Conflict of Interest Statement}

The authors have no conflicts of interest to disclose.

\section{Funding Sources}

There were no funding sources for this work.

\section{Author Contributions}

J.E. Juskewitch, E.K. Jacob, and M.A. DiGuardo were involved in the conception and drafting of this case report. C.D. Tauscher, S.K. Moldenhauer, and J.E. Schieber were involved in the acquisition of the case report data. All authors were involved in the analysis and interpretation of the case report data and manuscript revisions. All authors approved the final version of the manuscript for publication and agree to be accountable for all aspects on this work.

\section{References}

1 Ashley-Koch A, Yang Q, Olney RS. Sickle hemoglobin (HbS) allele and sickle cell disease: a HuGE review. Am J Epidemiol. 2000 May; 151(9):839-45.

2 Bender MA. Sickle cell disease. In: Adam MP, Ardinger HH, Pagon RA, Wallace SE, Bean LJ, Stephens K, et al., editors. GeneReviews(R) [Internet]. 2017. Available from: www.ncbi. nlm.nih.gov/books/NBK1377.

3 Niihara Y, Smith WR, Stark CW. A Phase 3 Trial of 1-Glutamine in Sickle Cell Disease. N Engl J Med. 2018 Nov;379(19):1880.

4 Alayed N, Kezouh A, Oddy L, Abenhaim HA. Sickle cell disease and pregnancy outcomes: population-based study on 8.8 million births. J Perinat Med. 2014 Jul;42(4):487-92.

5 Costa VM, Viana MB, Aguiar RA. Pregnancy in patients with sickle cell disease: maternal and perinatal outcomes. J Matern Fetal Neonatal Med. 2015 Apr;28(6):685-9.

6 Howard J, Oteng-Ntim E. The obstetric management of sickle cell disease. Best Pract Res Clin Obstet Gynaecol. 2012 Feb;26(1): 25-36.

7 Villers MS, Jamison MG, De Castro LM, James AH. Morbidity associated with sickle cell disease in pregnancy. Am J Obstet Gynecol. 2008 Aug;199(2):125.e1-5.

8 Nickel RS, Horan JT, Fasano RM, Meyer E, Josephson CD, Winkler AM, et al. Immunophenotypic parameters and RBC alloimmunization in children with sickle cell disease on chronic transfusion. Am J Hematol. 2015 Dec;90(12):1135-41.

9 Nickel RS, Hendrickson JE, Fasano RM, Meyer EK, Winkler AM, Yee MM, et al. Impact of red blood cell alloimmunization on sickle cell disease mortality: a case series. Transfusion. 2016 Jan;56(1):107-14.

10 Vichinsky EP, Earles A, Johnson RA, Hoag MS, Williams A, Lubin B. Alloimmunization in sickle cell anemia and transfusion of racially unmatched blood. N Engl J Med. 1990 Jun; 322(23):1617-21.

11 Vichinsky EP, Luban NL, Wright E, Olivieri N, Driscoll C, Pegelow CH, et al.; Stroke Prevention Trail in Sickle Cell Anemia. Prospective RBC phenotype matching in a stroke-prevention trial in sickle cell anemia: a multicenter transfusion trial. Transfusion. 2001 Sep;41(9):1086-92.

12 Yazdanbakhsh K, Ware RE, Noizat-Pirenne F. Red blood cell alloimmunization in sickle cell disease: pathophysiology, risk factors, and transfusion management. Blood. 2012 Jul; 120(3):528-37.

13 Aygun B, Padmanabhan S, Paley C, Chandrasekaran $\mathrm{V}$. Clinical significance of RBC alloantibodies and autoantibodies in sickle cell patients who received transfusions. Transfusion. 2002 Jan;42(1):37-43.

14 Banks M, Shikle J. Hyperhemolysis Syndrome in Patients With Sickle Cell Disease. Arch Pathol Lab Med. 2018 Nov;142(11): 1425-7.

15 Gardner K, Hoppe C, Mijovic A, Thein SL. How we treat delayed haemolytic transfusion reactions in patients with sickle cell disease. Br J Haematol. 2015 Sep; 170(6):745-56.

16 Siddon AJ, Kenney BC, Hendrickson JE, Tormey CA. Delayed haemolytic and serologic transfusion reactions: pathophysiology, treatment and prevention. Curr Opin Hematol. 2018 Nov;25(6):459-67.

17 Faas BH, Beckers EA, Simsek S, Overbeeke MA, Pepper R, van Rhenen DJ, et al. Involvement of Ser103 of the Rh polypeptides in G epitope formation. Transfusion. 1996 Jun; 36(6):506-11.

18 The Human RhesusBase, version 2.5.2, 2020. Available from: www.rhesusbase.info [updated March 18, 2020].
19 Wagner FF, Flegel WA. The Rhesus Site. Transfus Med Hemother. 2014 Oct;41(5): 357-63.

20 Unni N, Peddinghaus M, Tormey CA, Stack G. Record fragmentation due to transfusion at multiple health care facilities: a risk factor for delayed hemolytic transfusion reactions. Transfusion. 2014 Jan;54(1):98-103.

21 Ness PM, Shirey RS, Thoman SK, Buck SA. The differentiation of delayed serologic and delayed hemolytic transfusion reactions: incidence, long-term serologic findings, and clinical significance. Transfusion. 1990 Oct;30(8):688-93.

22 Stack G, Tormey CA. Detection rate of blood group alloimmunization based on real-world testing practices and kinetics of antibody induction and evanescence. Transfusion. 2016 Nov;56(11):2662-7.

23 Tormey CA, Stack G. The persistence and evanescence of blood group alloantibodies in men. Transfusion. 2009 Mar;49(3):505-12.

24 Tormey CA, Hendrickson JE. Transfusionrelated red blood cell alloantibodies: induction and consequences. Blood. 2019 Apr; 133(17):1821-30.

25 Hoffman JM, Flynn AJ, Juskewitch JE, Freimuth RR. Biomedical Data Science and Informatics Challenges to Implementing Pharmacogenomics with Electronic Health Records. Annu Rev Biomed Data Sci. 2020;3(1):289314.

26 Schwickerath V, Kowalski M, Menitove JE. Regional registry of patient alloantibodies: first-year experience. Transfusion. $2010 \mathrm{Jul}$; 50(7):1465-70.

27 van Gammeren AJ, van den Bos AG, Som N, Veldhoven C, Vossen RC, Folman CC. A national Transfusion Register of Irregular Antibodies and Cross (X)-match Problems: TRIX, a 10-year analysis. Transfusion. 2019 Aug; 59(8):2559-66. 